\title{
Características da população infantil atendida em triagem no período de 2000 a 2002 numa clínica-escola
}

\author{
Characteristics of children seen at a University \\ Psychology clinic from 2000 to 2002
}

\author{
Sandra Augusta de MELO \\ Hélvia Cristine Castro Silva PERFEITO²
}

\begin{abstract}
Resumo
Este artigo relata a experiência de um trabalho realizado no Centro de Psicologia Aplicada da Faculdade de Psicologia da Universidade Federal de Uberlândia que buscou levantar, a partir dos dados de atendimentos infantis realizados entre 2000 e 2002, características epidemiológicas e clínicas da demanda infantil atendida em triagem. Diversos aspectos dos 139 casos foram analisados em termos de incidência (porcentagens) e discutidos com embasamento clínico das supervisões de caso. Obteve-se que a demanda clínica deste serviço constitui, em sua maioria, de crianças que apresentam sintomas responsivos ao grupo familiar. Os dados permitiram, ainda, levantar hipóteses e sugerir novas pesquisas acerca das mudanças na família e nas funções parentais presentes na gênese dos problemas infantis que geram demanda clínica em psicologia.
\end{abstract}

Palavras-chave: triagem psicológica; clínica-escola de psicologia; queixas psicológicas; psicodiagnóstico infantil; dinâmica familiar.

\begin{abstract}
This paper describes the Psychology Applied Center experience from Faculdade de Psicologia da Universidade Federal de Uberlândia. It has aimed to identify, from 2000 to 2002 clinical infant data, children's epidemiological and clinical characteristics, considering reception process. Important aspects from the 139 cases had been analyzed in terms of incidence (percentages) and revised trough case supervision sessions. These analysis have shown the clinical demand is composed, in its majority, by children who present responsive symptoms to the familiar group. Data had also pointed out new hypotheses and new researches concerning family changes and parental functions relation to the infantile problems origin, two relevant topics of the psychological clinic demand.
\end{abstract}

Key words: psychological screening; University psychology clinic; psychological complaints; child psychodiagnosis; family psychodinamic.

Na cidade de Uberlândia, MG, há uma carência evidente por sistematização no registro de dados tanto estatísticos como descritivos das populações clínicas que buscam atendimento em saúde mental. Isso significa dizer que não se conhece o perfil da população que busca atendimento na rede pública.

Este trabalho surgiu da iniciativa de psicólogos que atuam no Centro de Psicologia Aplicada da Facul-

\section{UQ⿱艹⿴囗十}

1 Doutora, Centro de Psicologia Aplicada, Universidade Federal de Uberlândia. Av. João XXIII, 698, Santa Maria, 38408-056, Uberlândia, MG, Brasil. Correspondência para/Correspondence to: S.A. MELO. E-mail: <sandra_augusta@terra.com.br>.

2 Mestranda em Psicologia Clínica e Psicóloga; Centro de Psicologia Aplicada, Universidade Federal de Uberlândia. Uberlândia, MG, Brasil. 
dade de Psicologia da Universidade Federal de Uberlândia (CENPS - UFU), mediante a constatação da falta de dados sobre os atendimentos realizados no CENPS, a percepção da riqueza de informações geradas nos prontuários, e o desejo de avaliar o trabalho de triagem que vinha sendo desenvolvido, por meio de uma análise quantitativa e qualitativa sobre a origem dos pacientes, suas características, os encaminhamentos dados aos casos e seus índices de resolutividade. Isso motivou a criação de procedimentos de levantamento de dados que pudessem fornecer informações sobre a população atendida.

A escolha pela clientela infantil para a presente análise deve-se à alta demanda dessa faixa etária e dos pouquíssimos dispositivos públicos disponíveis para esse tipo de atendimento na cidade de Uberlândia, figurando, assim, como uma possível colaboração para ações preventivas em diversos níveis.

Esta é a segunda iniciativa de levantamento da clientela da clínica psicológica da UFU. Um levantamento epidemiológico geral foi realizado na década de 80 por Sanchez (1985). Entretanto, o levantamento de características da população afluente à clínica não foi uma prática constante nesses 20 anos, pois não foram criados procedimentos de levantamento estatísticoepidemiológicos que mantivessem e alimentassem a construção de dados dessa natureza.

Em outras clínicas-escola essa preocupação também aparece, como pode ser visto em Graminha e Martins (1993) e Borges (1996) em relação à caracterização da clientela na área de atendimento infantil. Também um levantamento geral da população clínica em Psicologia na cidade de São Paulo foi publicado por Ancona-Lopez em 1984. Esses trabalhos também se caracterizam como levantamentos pontuais e não mostram uma prática sistemática de registro de dados epidemiológicos e clínicos da população atendida.

Além da questão relacionada à necessidade de dados sobre as populações clínicas, suas demandas, os tipos de tratamento e sua resolutividade, a crescente busca por atendimento psicológico às crianças constitui em si um assunto importante a ser investigado e discutido. Esse aumento pode estar associado a diversos fatores cuja discussão é complexa e abrange fatores culturais, históricos, de avanços da ciência, e outros, mas essa complexidade não encontra lugar de discussão neste artigo.

Entretanto, para este estudo que deriva da prática profissional em uma clínica-escola de Psicologia, seria praticamente impossível discutir atendimentos infantis em seus aspectos epidemiológicos e principalmente clínicos sem abordar a questão do papel parental e da família na construção das dificuldades ou da saúde emocional da criança.

Para Lipovetsky (2004) o grande problema da hipermodernidade (como é chamada a época atual) éa fragilização dos indivíduos inseridos numa sociedade complexa e paradoxal, carente de antigas formas de coesão social. Esse autor aponta o paradoxo de nossa sociedade hiperfuncional do ponto de vista científicotecnológico e, ao mesmo tempo, disfuncional na construção de formas de convivência com o crescimento de patologias (depressão, ansiedade, suicídio, pânico, anorexia), criminalidade e violência.

O conceito de hipermodernidade e a discussão do autor (Lipovetsky, 2004) ilustram como as vicissitudes histórico-culturais relacionadas às mudanças dos modos de produção e de organização dos grupamentos humanos atingem a família e as funções parentais, relacionando-as com a sintomatologia infantil - o que é de nosso especial interesse no tema aqui tratado.

Na perspectiva psicanalítica, Jacques Lacan inaugurou a perspectiva que estabelece uma relação entre o inconsciente da criança e o desejo parental, gerando um requestionamento da clínica e determinando novos modos de abordagem da determinação psíquica, revertendo, assim, a perspectiva endogenista e colocando os sintomas da criança diante de outros impasses, ou seja, concebendo a criança como sintoma da mãe, do casal ou da família (Bleichmar, 1994).

Os sintomas podem ser classificados em duas categorias: estruturais e reativos. Os estruturais dizem respeito ao próprio sujeito e é constitutivo dele, cuja verdade se faz representar por esse sintoma. Os reativos, ou também chamados de manifestações sintomáticas, são aqueles identificados como produto da organização parental inconsciente e constituem-se como respostas da criança às neuroses de seus pais (Kupfer, 1994).

A criança, para se fazer ouvir, poderá produzir sintomas naqueles lugares insuportáveis para os pais 
quando aparecem no lugar do desejo reprimido, no lugar de algo que ficou bloqueado no desenvolvimento de suas relações inconscientes com seus pais, reatualizando, dessa maneira, conflitos enterrados, não resolvidos.

O sintoma, diz Rosenberg (1994), é o que leva à consulta como máscara, cujo papel oculta o acontecimento perturbador ou o texto original. Um sintoma é algo a partir do qual é possível encontrar a palavra perdida, o não dito do discurso parental. Os filhos expressam em seus sintomas os pontos cegos e os impasses de seus pais e sofrem com as falhas na sustentação de suas funções parentais.

Com o psiquismo ainda em formação, com determinantes de ordem interna e externa (o que é próprio da constituição da criança e o peso do mundo desejante do outro - pais), o eu ainda incipiente tenta satisfazer o desejo dos pais e há uma superposição na formação da subjetividade entre a dinâmica psíquica da criança e de seus progenitores. O desejo da criança se confunde com o dos pais, o supereu de um com o outro, a função egóica da mãe com as possibilidades da criança, não se estabelecendo uma clara definição dentro-fora (Rosenberg, 1994).

A perspectiva interpsíquica (categoria de sintomas infantis reativos), em que o fundamental está na relação com o outro, assim como a intrapsíquica (categoria dos sintomas descritos como estruturais), em que o fundamental é o indivíduo, mostram que, quando se trata de estudar uma população infantil, é necessário considerar holisticamente as questões abordadas, muito embora nem todas elas possam ser assumidas numa discussão como esta sob pena de o foco se perder.

\section{Método}

\section{Contextualização}

Como o município está dividido em distritos sanitários de acordo com as normas do Sistema Único de Saúde (SUS) e cada distrito possui seus dispositivos de atendimento à saúde mental que se responsabiliza pela população de sua área de abrangência, o CENPS destina-se a atender o setor leste da cidade de Uberlândia, no qual está situado. Esses dispositivos têm autonomia quanto à forma de atendimento da população a eles atribuída.

No CENPS, entre 2000 e 2002, o atendimento era feito mediante procura espontânea dos pacientes que eram triados por psicólogos e estagiários do plantão psicológico. O plantão era realizado em dias fixos da semana para atendimento das diferentes faixas etárias: infantil, adolescente e adulto. A partir da recepção sem marcação prévia, os pacientes passavam por um processo de triagem, bastando para isso serem residentes do setor leste da cidade.

A triagem psicológica, tal qual realizada durante este estudo, tinha um caráter ao mesmo tempo psicodiagnóstico e interventivo que durava aproximadamente cinco sessões, ocorrendo, posteriormente, um encaminhamento do caso ou o atendimento pelo próprio triador.

Os triadores eram sempre estagiários dos últimos três períodos do curso de Psicologia, supervisionados por psicólogos do CENPS. Os dados da triagem eram registrados em um roteiro de anamnese e em folhas de relato de sessão. Ao término do processo de avaliação, os dados eram resumidos em súmulas de prontuários destinados à pesquisa.

\section{Participantes}

Dos cento e trinta e nove pacientes infantis atendidos em triagem psicológica em 2000, 2001, 2002 no CENPS, 88\% deles eram originários do setor leste e 12\% de outros setores do distrito sanitário da cidade de Uberlândia, MG, eram de diferentes classes sociais, caracterizando demanda espontânea de serviço de saúde pública.

\section{Procedimentos}

Este trabalho tem como fontes de dados os prontuários da população infantil triada entre 2000 e 2002 e as supervisões clínicas desses casos realizadas pelos psicólogos para com alunos estagiários do curso de Psicologia no estágio Plantão Psicológico. A partir de súmulas dos prontuários, os dados foram adaptados em registros numéricos e tabulados. Nesse sentido, vale 
salientar que este trabalho não foi inicialmente programado para ser uma pesquisa, nem os dados foram colhidos para fins de investigação, mas um trabalho em que dados institucionais foram tratados visando oferecer respostas a uma questão concreta que é a caracterização da população atendida. Portanto, situa-se entre um relato de experiência e uma pesquisa.

Nesse processo de transformar os resultados da ação desempenhada em dados de pesquisa, uma das dificuldades foi a quantificação das queixas, pois procurou-se valorizar os relatos originais (falas dos pacientes registradas nos prontuários), embora, neles, as queixam apareçam com diferentes tipos de registro, ora em linguagem leiga, outras vezes com terminologias técnicas, equivocadas ou não. Para transformar aquilo que era descritivo em dados quantificáveis, foi necessário agrupar as queixas em categorias. A opção foi por identificar a perspectiva da queixa do ponto de vista do acompanhante, ou seja, qual aspecto da criança ou em relação à criança era motivo de queixa. Devido ao sentido da palavra "queixa", elas foram classificadas quanto ao aspecto que incomodava os pais ou que motivou que trouxessem a criança para o atendimento.

Para isso, quatro psicólogos experientes que compõem a equipe do CENPS chegaram ao consenso de que as queixas, tal qual aparecem nos prontuários das crianças (totalizando 106 tipos), poderiam se encaixar em uma das seguintes categorias: queixas comportamentais; queixas afetivo-emocionais; queixas escolares; queixas relacionais; queixas cognitivas; queixas fisiológico-funcional-somáticas. Após isso, cada um dos profissionais atuou como juiz, avaliando cada uma das 106 diferentes queixas e classificando-as dentro das categorias. Onde houve divergência nas respostas, discussões foram realizadas até que se chegasse ao consenso quanto à classificação da queixa.

Assim, todas as queixas foram classificadas dentro de uma das seis categorias, tendo como referência ao que motivou a mãe ou responsável a buscar ajuda para a criança ou que despertou o adulto para essa necessidade. A Tabela 1 gerada a partir do julgamento dos juízes quanto à classificação das queixas segundo as categorias.

Dessa forma, uma criança era classificada quanto

242 à apresentação ou não de cada uma das queixas, já que os tipos de queixa não se excluem mutuamente. As porcentagens obtidas dizem respeito, portanto, à presença ou ausência de cada uma delas.

O diagnóstico, obtido em discussão durante as supervisões, foi realizado segundo a Classificação Internacional de Doenças - CID 10, nas categorias F-Transtornos mentais e comportamentais e Z - Fatores influenciando o estado de saúde e contato com serviços de saúde. Em alguns casos, foram necessários dois diagnósticos em F.

A resolução em triagem abrangeu as seguintes categorias: alta em triagem; abandono sem justificativa; abandono com justificativa; encaminhamento estagiário plantão; encaminhamento supervisor plantão; encaminhamento outros estagiários; encaminhamento supervisor docente; encaminhamento atendimento externo.

\section{Análise dos dados}

As freqüências sobre os dados epidemiológicos e clínicos foram obtidas e correlacionadas com as análises realizadas nas supervisões clínicas dos casos, possibilitando assim as discussões e o levantamento de hipóteses que poderão gerar novas pesquisas no futuro.

Os dados apresentados são: idade, sexo, com quem reside, escolaridade, encaminhamento de origem, queixas, classificação diagnóstica, e grau de resolução daqueles pacientes infantis que passaram pelo processo de triagem no período de 2000 a 2002.

Na discussão, busca-se dialogar com análises realizadas durante as supervisões dos casos e com autores que apontam caminhos para a compreensão dos dados obtidos.

\section{Resultados}

A população infantil atendida nos plantões em triagem no período de 2000 a 2002 na Clínica Escola da UFU apresenta as características seguintes: quanto à idade, as maiores freqüências de procura por atendimento seguem a seguinte ordem: 9 anos de idade (19,4\%), 10 (15,1\%), 6 (14,4\%), 7 (13,7\%) e 4 anos (12,2\%). É possível observar que a faixa etária de maior demanda 
Tabela 1. Classificação das queixas segundo categorias criadas pelos quatro juízes.

\begin{tabular}{|c|c|c|c|c|c|c|}
\hline Classficação & Comportamental & Emocional-afetiva & Escolar & Relacional & Cognitiva & $\begin{array}{c}\text { Fisiológico/ } \\
\text { Funcional-somática }\end{array}$ \\
\hline Queixas & $\begin{array}{l}\text { Agitação } \\
\text { Agressividade } \\
\text { Arrancar cabelos } \\
\text { Assanhamento } \\
\text { Birra } \\
\text { Brigar em casa } \\
\text { Comer demais } \\
\text { Comportamentos } \\
\text { regredidos (chupar } \\
\text { dedo/ chupeta e } \\
\text { mamadeira) } \\
\text { Desobediência } \\
\text { Desorganização } \\
\text { Distúrbio de } \\
\text { comportamento } \\
\text { Falta de iniciativa } \\
\text { Fugir de casa } \\
\text { Fumar } \\
\text { Gagueira } \\
\text { Hiperatividade } \\
\text { Inquietude } \\
\text { Irresponsabilidade } \\
\text { Mentiras } \\
\text { Morder } \\
\text { Mudança de } \\
\text { comportamento } \\
\text { Pirraça } \\
\text { Problema de fala } \\
\text { Rebeldia } \\
\text { Revolta } \\
\text { Roer unhas } \\
\text { Roubo } \\
\text { Silêncio } \\
\text { susolongado de drogas ou } \\
\text { Suspeita }\end{array}$ & $\begin{array}{l}\text { Angústia } \\
\text { Ansiedade } \\
\text { Baixa auto-estima } \\
\text { Ciúme } \\
\text { Dependência } \\
\text { Depressão } \\
\text { Dificuldade de } \\
\text { ficar só } \\
\text { Fobia } \\
\text { Impulsividade } \\
\text { Inibição } \\
\text { Insegurança } \\
\text { Intolerância } \\
\text { Introspecção } \\
\text { Irritação } \\
\text { Mau humor } \\
\text { Medo } \\
\text { Nervosismo } \\
\text { Pânico } \\
\text { Sentimento de } \\
\text { vazio } \\
\text { Solidão } \\
\text { Tristeza }\end{array}$ & $\begin{array}{l}\text { Agressividade na } \\
\text { escola } \\
\text { Dificuldade } \\
\text { escolar } \\
\text { Expulso da escola } \\
\text { Falta de interesse } \\
\text { na escola } \\
\text { Matar aulas } \\
\text { Necessidade de } \\
\text { orientação } \\
\text { vocacional } \\
\text { Queda no } \\
\text { rendimento } \\
\text { escolar } \\
\text { Queixas advindas } \\
\text { da escola } \\
\text { Tensão } \\
\text { pré-vestibular }\end{array}$ & $\begin{array}{l}\text { Agarrada à mãe } \\
\text { Agressividade na } \\
\text { família } \\
\text { Andar em má } \\
\text { companhia } \\
\text { Brigas em geral } \\
\text { Brigas em casa } \\
\text { Dificuldade de } \\
\text { fazer ou manter } \\
\text { amigos (de } \\
\text { socialização) } \\
\text { Dificuldade de } \\
\text { relacionamento } \\
\text { (geral) } \\
\text { Dificuldade de } \\
\text { relacionamento } \\
\text { com os filhos } \\
\text { Isolamento } \\
\text { Mãe quer } \\
\text { acompanhamento } \\
\text { para o filho } \\
\text { Não gosta de ser } \\
\text { abraçado e } \\
\text { beijado } \\
\text { Problemas } \\
\text { conjugais } \\
\text { Relacionamento } \\
\text { difícil } \\
\text { Retraimento } \\
\text { Separação na } \\
\text { família } \\
\text { Timidez }\end{array}$ & $\begin{array}{l}\text { Confuso } \\
\text { Desatenção ou } \\
\text { Falta de atenção } \\
\text { Desinteresse } \\
\text { Lentidão para } \\
\text { aprender } \\
\text { Problema de } \\
\text { aprendizagem }\end{array}$ & $\begin{array}{l}\text { Aftas } \\
\text { Alergia } \\
\text { Alteração de peso } \\
\text { Constipação } \\
\text { Crises convulsivas } \\
\text { Diarréia } \\
\text { Doença física } \\
\text { Dores } \\
\text { Encoprese } \\
\text { Enurese } \\
\text { Estresse } \\
\text { Falta de apetite } \\
\text { Febres } \\
\text { Fraqueza } \\
\text { Insônia } \\
\text { Obesidade } \\
\text { Pesadelos } \\
\text { Queda de cabelo } \\
\text { Suor } \\
\text { Tontura }\end{array}$ \\
\hline
\end{tabular}

está entre os 6 e os 10 anos, concentra-se na idade de 9 anos, e que há um pico, também, por procura de crianças com idade de 4 anos.

Assim como Ancona-Lopez (1984) e Barbosa e Silvares (1994), a faixa etária de maior demanda está entre os 6 e os 10 anos de idade, com um índice significativo, no caso da presente pesquisa, também aos 4 anos.

Quanto ao sexo, observa-se que os meninos constituem $62,6 \%$ da população atendida no plantão psicológico enquanto as meninas são 37,4\%. O sexo masculino aparece como predominante na população clínica infantil em uma proporção de mais de três meninos para cada duas meninas para os quais se busca atendimento psicológico. Confirmam esse fato as pesquisas de Ancona-Lopez (1984), Borges (1996) e Graminha e Martins (1993). Isso mostra que, em 20 anos, a demanda infantil para o sexo masculino continua com maior incidência.

Outra questão estudada foi com quem a criança reside. Pode-se observar a predominância de crianças que residem com seus pais (58,3\%), seguidas por aquelas 
que moram com sua mãe (20,9\%), familiares (9,4\%) e a seguir com pai ou mãe em novo casamento $(5,8 \%)$.

Sanchez, tratando da população geral, encontrou, em 1985, que $72,5 \%$ dos pacientes atendidos no CENPS residiam com familiares, isto é, pais ou sogros. No presente estudo, tratando-se de crianças, os dados mostram que quase $85,0 \%$ delas moram com os pais, só com a mãe ou com o pai ou ainda com um deles em seu segundo casamento.

A escolaridade dos pacientes também foi levantada e pôde-se observar que a maior concentração se dá na pré-escola (28,0\%), lembrando que dentro do item pré-escola constam crianças que freqüentam desde a escola maternal até o terceiro período ou alfabetização, ou seja, abaixo ou igual a seis anos de idade. Em seguida, vem a primeira série, que apresentou 18,0\% e, logo após, a quarta (14,0\%) e terceira série (12,0\%).

Com relação aos encaminhamentos da criança ao atendimento, deve-se considerar o enviezamento relacionado ao acordo com um centro de saúde que, não podendo conter a demanda, encaminhava, já no acolhimento psicossocial, os pacientes infantis à clínica. Entretanto, ainda vale observar que o maior índice é relativo à procura espontânea dos pais (33,0\%), seguido por encaminhamentos médicos (22,0\%). Esse fato pode estar associado à inserção do CENPS numa universidade que conta com hospital de clínicas.

Apesar desse fato, que tende a aumentar os encaminhamentos médicos, observa-se que, em relação à pesquisa de Ancona-Lopez (1984), houve uma inversão bastante reveladora que mostra um aumento significativo de procura por parte dos pais, enquanto na pesquisa daquela autora a porcentagem maior é de encaminhamento por terceiros. Isso também é válido em relação ao trabalho de Sanchez (1985).

Esse aumento significativo é uma questão importante, pois aponta para o que inicialmente foi discutido neste trabalho acerca da fragilização do indivíduo hipermoderno, demonstrando a carência de referenciais internos e sujeitos ao tecnicismo e especialidades do saber, buscando e depositando nos profissionais especializados a resposta para suas angústias vivenciais.

Nesse ponto, foram avaliadas as presenças ou ausências de queixas nas seis categorias definidas (comportamental; afetivo-emocional; escolar; relacional; cognitiva; fisiológico-funcional-somática) e computado o número de crianças em que estas estavam presentes.

A maior parte das crianças trazidas ao plantão psicológico da CENPS, 60,4\%, chegou para o atendimento com queixa comportamental e 51,0\% tinham queixas que puderam ser classificadas como emocionais ou afetivas.

As queixas escolares estão presentes em 24,0\% dos casos; as que se referem a dificuldades de relacionamento ou relacionais constam em 14,0\% dos casos atendidos; problemas classificados como cognitivos apareceram em 14,0\% dos casos atendidos e queixas que se apresentam como fisiológico-funcionalsomáticas estão em 23,0\% dos casos.

O diagnóstico segundo a CID 10 gerou duas classificações em duas classes da categoria F, sendo o mais evidente chamado de diagnóstico principal e o outro de secundário.

Tabela 2. População infantil atendida nos plantões em triagem no período de 2000 a 2002 na Clínica-Escola da UFU, distribuída quanto à classificação diagnóstica principal em transtornos mentais e comportamentais, utilizando a CID 10.

\begin{tabular}{|c|c|c|}
\hline $\begin{array}{l}\text { Diagnóstico de transtorno } \\
\text { mental e comportamental }\end{array}$ & $\begin{array}{l}\text { Freqüência } \\
\text { (n) }\end{array}$ & $\begin{array}{l}\text { Porcentagem válidados } \\
\text { casos que apresentam } \\
\text { diagnóstico nesta classe }\end{array}$ \\
\hline F40 & 3 & 4,7 \\
\hline F41 & 1 & 1,6 \\
\hline F43 & 3 & 4,7 \\
\hline F45 & 6 & 9,4 \\
\hline F51 & 1 & 1,6 \\
\hline F54 & 1 & 1,6 \\
\hline F64 & 1 & 1,6 \\
\hline F80 & 5 & 7,8 \\
\hline F81 & 4 & 6,3 \\
\hline F84 & 1 & 1,6 \\
\hline F90 & 4 & 6,3 \\
\hline F91 & 6 & 9,4 \\
\hline F92 & 3 & 4,7 \\
\hline F93 & 12 & 18,8 \\
\hline F94 & 2 & 3,1 \\
\hline F95 & 1 & 1,6 \\
\hline F98 & 10 & 15,6 \\
\hline $\begin{array}{l}\text { Total de sujeitos que } \\
\text { apresentam diagnóstico } \\
\text { nessa classe }\end{array}$ & 64 & 46,0 \\
\hline $\begin{array}{l}\text { Não apresenta diagnóstico } \\
\text { nessa classe }\end{array}$ & 75 & 54,0 \\
\hline Total & 139 & 100,0 \\
\hline
\end{tabular}

Fonte: prontuários de pacientes triados na CENPS entre 2000 e 2002. 
A distribuição dentro das classes é exposta na Tabela 2 e as classes podem ser identificadas com o auxílio do CID 10, não constando no texto para não estendê-lo demais.

Importante notar que 54,0\% da demanda infantil não apresentam diagnóstico na classe relacionada a transtornos mentais e comportamentais, enquanto 46,0\% recebem essa classificação. Esse item é um dado que traz uma indicação epidemiológica importante, que será discutida posteriormente.

Tabela 3. População infantil atendida nos plantões em triagem no período de 2000 a 2002 na Clínica-Escola da UFU, distribuída quanto a uma segunda classificação diagnóstica em transtornos mentais e comportamentais, utilizando a CID 10

\begin{tabular}{lcc}
\hline $\begin{array}{l}\text { Segundo diagnóstico de transtorno } \\
\text { mental e comportamental }\end{array}$ & Freqüência (n) & (\%) \\
\hline F45 & 3 & 2,2 \\
F63 & 1 & 0,7 \\
F80 & 1 & 0,7 \\
F81 & 1 & 0,7 \\
F83 & 1 & 0,7 \\
F93 & 2 & 1,4 \\
F98 & 4 & 2,9 \\
Total de sujeitos que apresentam uma & 13 & 9,4 \\
segunda classificação diagnóstica & & \\
nessa classe & & \\
Não apresentam diagnóstico nessa & 126 & 90,6 \\
classe & & \\
\hline Total & 139 & 100,0 \\
\hline
\end{tabular}

Fonte: prontuários de pacientes triados na CENPS entre 2000 e 2002.

Tabela 4. População infantil atendida nos plantões em triagem no período de 2000 a 2002 na Clínica-Escola da UFU, distribuída quanto a fatores influenciando o estado de saúde e contato com serviços de saúde segundo a CID 10.

\begin{tabular}{lcc}
\hline $\begin{array}{l}\text { Diagnóstico em Fatores } \\
\text { influenciando o estado de saúde }\end{array}$ & Freqüência (n) & $(\%)$ \\
\hline Z60 & 4 & 2,9 \\
Z61 & 11 & 7,9 \\
Z62 & 30 & 21,6 \\
Z63 & 63 & 45,3 \\
Z87 & 1 & 0,7 \\
Total de sujeitos que apresentam & 109 & 78,4 \\
diagnóstico nessa classe & & \\
Não apresentam diagnóstico nessa & 30 & 21,6 \\
classe & & \\
\hline Total & 139 & 100,0 \\
\hline
\end{tabular}

Fonte: prontuários de pacientes triados na CENPS entre 2000 e 2002.
Os dados da Tabela 3 indicam que 9,4\% dos casos atendidos (13 casos) foram classificados em dois diagnósticos em transtornos mentais e comportamentais.

As classes "Z" do CID 10 são nomeadas como "fatores influenciando o estado de saúde e contato com serviços de saúde", e oferecem possibilidade de identificar alguns aspectos importantes associados aos quadros clínicos dos pacientes, pois revelam associações com o ambiente, a família e eventos da infância. Esses fatores uma vez identificados nos atendimentos e discutidos nas supervisões foram classificados na Tabela 4.

Dos 139 casos atendidos, 109 apresentam diagnósticos relacionados a questões familiares e/ou de suporte ambiental (Tabela 4).

A resolução ou os encaminhamentos aos atendimentos foram quantificados após a etapa de triagem. Do total, 48,2\% dos casos continuaram sob a responsabilidade dos estagiários triadores e foram por eles atendidos; 18,0\% da demanda tiveram suas questões resolvidas durante o processo de triagem e receberam alta; 10,0\% dos casos foram atendidos pelo supervisor da triagem infantil, ou seja, num total de $76,2 \%$ resolvidos dentro do serviço de plantão. O abandono soma 9,3\% e os encaminhamentos para outros serviços internos ou externos $13,6 \%$.

\section{Discussão}

Vale advertir que poucos trabalhos publicados permitiram comparações ou forneceram parâmetros para a discussão dos dados encontrados relativos especificamente a populações clínicas infantis. Mesmo Sanchez (1985), que realizou pesquisa na mesma instituição, por ter investigado a população como um todo e ter dado um outro delineamento ao levantamento de dados, não pôde ser usado para comparações com este trabalho, que é mais específico e direcionado à população infantil. Assim, muitas vezes, foi necessário ancorar a discussão em trabalhos que abrangem uma população ampla e, por isso, mais gerais e nem sempre apropriados.

Foi em Ancona-Lopez (1984) que se pôde encontrar algumas possibilidades de interlocução (embora não seja possível uma correlação) a respeito 
dos dados epidemiológicos encontrados e analisados acima. Alguns como sexo e idade confirmam os achados daquela autora de praticamente vinte anos atrás. A única diferença aparece numa concentração de procura por atendimento aos quatro anos de idade, mas que não é possível afirmar ser uma mudança significativa em relação àquele estudo.

Entretanto, no que diz respeito àqueles que podem levar a hipóteses sobre a dinâmica familiar imbricada na causalidade dos problemas com a criança, alguns pontos chamam a atenção por não serem concordantes com aquela autora.

Pôde-se verificar que a incidência das queixas concentra-se nos comportamentos e condutas (60\%) e sintomas emocionais (51\%) das crianças. As queixas ligadas à escola perfazem 24\% dos casos e em geral não aparecem isoladas. Assim, o que parece angustiar e incomodar os pais são questões relacionadas à normalidade ou não, à presença de doença mental ou não: "será que meu filho é normal?", enquanto a discussão realizada na pesquisa de Ancona-Lopes (1984) na década de 80, enfatiza as angústias vivenciadas pelos pais em relação ao fracasso dos filhos e especificamente ao universo escolar e de aprendizagem, como motivadores para a busca por atendimento psicológico.

Em uma pesquisa mais recente, Affonso e Mota (2002) analisaram 108 prontuários de crianças de 2 a 12 anos atendidas em psicodiagnóstico em uma clínica psicológica (curso de Psicologia da UniFMU) com o objetivo de associar as queixas das crianças com o relacionamento familiar. Verificaram que dependendo do problema da criança há um tipo específico de vínculo pais-filhos: nos distúrbios de conduta o tipo de vínculo predominante é abandono e negligência educacional e dificuldades em lidar com os limites educacionais; nos distúrbios de socialização, além do abandono e negligência, encontraram também exigência e divergência educacional.

Embora não haja possibilidades de ser realizado um estudo comparativo com a presente pesquisa, é interessante verificar a associação apontada pelos autores entre o suporte familiar e os sintomas.

A partir dos dados quantitativos e das supervisões clínicas dos casos, observaram-se indica- tivos de uma mudança na expectativa e preocupação dos pais em relação aos filhos: hoje em dia, além da preocupação com o sucesso e a crença de que o rendimento escolar o determina, os pais reconhecem outras dimensões na constituição da criança (comportamental, emocional, de normalidade versus anormalidade, etc.). Essa observação necessita de novas e mais profundas investigações, mas merece ser pontuada.

Outro ponto relevante notado é que os pais das crianças trazidas aos atendimentos parecem ainda não perceber a criança como um processo em construção em que a dinâmica familiar, suas personalidades, suas funções parentais estão implicadas. Os pais se alienam daquilo que percebem de "errado" com os filhos.

Essas observações, embora não conclusivas, parecem encontrar lugar em importantes e atuais estudos sobre os processos de mudança e transformações ocorridas nas famílias e questionamentos de seus efeitos sobre a infância (Biasoli-Alves \& Simionato-Tozo, 1998; Ferez-Carneiro, 1998; Souza, 1997).

Observando os dados de classificação diagnóstica, evidencia-se que aqueles relacionados às dificuldades ligadas ao ambiente familiar e suporte parental são atribuídos a um número muito maior de casos do que aqueles em que transtornos mentais e comportamentais propriamente ditos possam ser apontados, numa proporção de 109 casos para 64 .

Em 139 casos, somente 30 deles estão classificados com um transtorno mental ou comportamental instaurado, 34 outros casos receberam, além do diagnóstico em transtorno mental ou comportamental, um outro que se refere a problemas no ambiente familiar e em 75 casos é possível identificar somente problemas familiares e/ou de suporte ambiental dos quais a criança é o porta-voz. Isso pode ser identificado comparando-se as Tabelas 2, 3 e 4.

Pode-se compreender esses resultados dentro da perspectiva intersubjetiva em que o sintoma infantil expresso (na grande maioria dos casos analisados) é um sintoma reativo e se dá na ordem da relação pais-criança, denunciando algo adoecido nessa relação e que advém dos pais.

Vale notar que mais de 18\% dos casos atendidos em triagem psicológica puderam ser solucionados 
durante o processo de triagem. Isso significa que tiveram alta em até quatro sessões de atendimento familiar. Esse dado aponta que, em 18\% dos problemas identificados em crianças por seus responsáveis, a possibilidade de um lugar onde a família pudesse pensar e refletir sobre si mesma esgotou a necessidade de encaminhamento para a psicoterapia.

Há uma discussão bastante importante e atual que é trazida à tona quando se observam os dados aqui apresentados: as mudanças familiares e as novas configurações dos lugares ocupados pelos membros da família, mais especificamente, quanto à função materna e paterna, na gênese dos problemas psicológicos das crianças.

Roudinesco (2003), em seu livro "A família em desordem", discute a família mutilada de hoje, feita de feridas íntimas e violências silenciosas em relação com a família autoritária de outrora, na qual o domínio era paterno. Hoje o pai fornece uma imagem invertida de si mesmo, deixando transparecer um eu descentrado, autobiográfico e individualizado.

O declínio da função paterna se encaminha desde o século XVIII e as mudanças do papel da mulher na sociedade geram mudanças no casal e na constituição dos núcleos familiares, tornando-se primordial a relação entre mãe e filho, à medida que o número de divórcios e recomposições parentais aumenta (Roudinesco, 2003).

Com isso, a família torna-se um lugar de poder descentralizado e de múltiplas aparências. Surgem denominações como: famílias co-parentais, recompostas, biparentais, multiparentais, pluriparentais ou monoparentais. Diante dessa multiplicidade, complexidade e indefinição de papéis, a família também se vê atingida, e os pais, fragilizados em suas funções. 0 comprometimento do grupo familiar traz como conseqüência a exacerbação das dificuldades infantis (Roudinesco, 2003).

Confirmando isso, no presente estudo aparecem 75 casos identificados com problemas ligados ao suporte familiar e ambiental, apontando para a precária situação psicológica familiar. E reafirmando esse fato, vale a pena assinalar que o referido tema é sempre o principal abordado durante as supervisões dos casos clínicos.

Outra questão que merece ser discutida - ainda que a título de hipótese a ser examinada em novas pesquisas - refere-se ao esvaziamento da maternagem, que se observa em grande parte dos casos atendidos, especialmente esses 75 comentados acima.

Ribeiro (2004), apoiada em Winnicott, alerta para as dificuldades que podem advir para a criança em decorrência de variações no manejo quando mais de uma pessoa assume os cuidados iniciais de um bebê e destaca duas razões ao considerar a mãe a pessoa mais indicada para cuidar de sua criança: o seu amor por ela, que permite uma adaptação às suas necessidades sem ressentimento e o fato de estar mais bem preparada para oferecer um ambiente rotineiro, com uma técnica de cuidados pessoais, proporcionando assim um ambiente emocional adequado.

Esse é um aspecto a ser considerado quando se pensa na delegação cada vez mais precoce das funções parentais a instituições educacionais, babás, avós, etc, que não assumem de fato a maternagem.

Observa-se que, se a educação e o cuidado dos filhos ficam a cargo de instituições educacionais, a observação e a resolução de dificuldades e problemas com os filhos também têm sido delegadas. Assim que identificam um problema com a criança, seja ele comportamental, afetivo, somático sem causa orgânica, de desempenho escolar ou de relacionamento, os pais, esvaziados de suas funções, deslocam-nas para profissionais especializados, fazendo deles os depositários daquilo que, a priori, lhes caberia pensar e resolver na relação com o filho. Os indicativos máximos disso encontrado neste estudo são os 18\% de casos resolvidos durante a triagem e os 75 (54\%) casos em que não se pôde encontrar algo para se considerar um diagnóstico de transtorno mental ou comportamental, mas somente dificuldades no suporte ambientalfamiliar.

Observou-se que o lugar pensante da mãe que recorre ao serviço de Psicologia em relação a sua criança é quase inexistente, e que ela ocupa uma posição distante e assujeitada, ou seja, não se coloca como pertencente ou implicada na situação em questão. Em grande parte dos casos atendidos, quando havia um 
problema que apontasse para o universo psicológico, imediatamente ocorria a busca de um psicoterapeuta, sem nenhuma tentativa prévia de compreensão da situação.

Essa mãe que assim se apresenta é o personagem contemporâneo que vive em condições de grande mutabilidade e turbulência, esvaziada de sentido - o que opera contra a construção de uma vida interior (que requer tempo e espaço) e que promove a destruição do domínio psíquico, ou seja, essa mãe é o representante do homem moderno (ou hipermoderno) que prescinde da representação das próprias experiências a que chamamos vida psíquica (Kristeva, 2002).

Nesse contexto, a mãe desautoriza-se de seu saber, e a ciência insuflada pela hipermodernidade, dentro de sua dinâmica técnico-científica, em suas múltiplas especialidades, toma a criança contemporânea e apropria-se de seu desenvolvimento psicológico, cognitivo, afetivo, segmentando-a. Novos pares formam-se: a mãe e o pediatra, a mãe e a psicopedagoga, a mãe e a psicóloga, a mãe e a nutricionista (Santos, 2005).

A análise dos atendimentos infantis e familiares realizados no CENPS leva à hipótese de que os pais, na atual configuração familiar e social, sofrem de um sentimento de impotência e incapacidade de pensar sua própria criança. A busca por psicólogos, em grande parte dos casos, acaba tendo por finalidade encobrir as faltas paterna e materna.

Debieux (2001) discute as vicissitudes da família frente à crescente destituição do saber em relação aos seus filhos que leva à busca por ajuda especializada. Alerta que na presente cultura não foram criados dispositivos eficazes para substituir a família em sua função de assegurar a constituição subjetiva dos filhos e de garantir a eficácia da transmissão dos significantes fundamentais da filiação e da sexualidade.

Alguns pontos podem ser levantados para discutir essa fragilização do grupo familiar. Um deles é a condição atual da mulher no plano social, econômico e profissional. Na configuração familiar patriarcal, esse lugar da mulher era inexistente, mas as mudanças trouxeram como conseqüência o tempo reduzido de convívio com os filhos e um distanciamento de acesso do adulto ao mundo infantil, em que os pais"adultizam" os filhos. Às crianças é exigido lidar com questões para as quais elas não estão preparadas, e os pais não conseguem compreender o pedido, a demanda de seus filhos, porque não se identificam com o mundo infantil. A criança é submetida, nesse processo, à solidão, ao desamparo, dentro de sua própria casa.

Ou seja, o distanciamento entre os pais e seus filhos, fruto da vida moderna, provoca um bloqueio na comunicação e um desconhecimento, tornando os pais alheios às necessidades emocionais infantis. Assim, há um sentimento de estranheza quando a criança apresenta dificuldades e os pais se sentem na incapacidade de propor soluções.

Alguns autores têm discutido o aumento do narcisismo nas relações humanas, em que o autocentramento narcísico do sujeito constitui terreno fértil para as diversas formas de desqualificação do objeto e o não reconhecimento desse em sua diferença, em que o outro é manipulado como objeto de gozo próprio. Ou seja, as relações atuais apontam a ocorrência de uma substituição do investimento libidinal do objeto por investimentos narcísicos (Bauman,1998).

Santos (2005) propõe um pensamento ousado acerca da relação pais-criança em que os pais, estimulados a consumir (elemento característico da hipermodernidade), produzir, e ascender socialmente, destinam um outro lugar psíquico aos filhos, em seu desejo e em sua economia libidinal: os filhos tornandose parte cada vez maior da realização narcísica dos pais.

Nesse sentido, podemos entender a inadequação que se revela nessas relações em função da demanda narcísica aumentada e da impossibilidade de olhar para uma criança percebendo sua diferença - aquilo que lhe é próprio - e ser capaz de suportar o sofrimento que nela se instala. O homem narcísico, - o pai ou a mãe narcísica - toma o sintoma ou a dificuldade da criança como uma falha narcísica e isso lhe é insuportável.

Soma-se a essa discussão o fato de que 58,3\% dos casos atendidos corresponderem a crianças que residem com ambos os pais, e pode-se levantar a suspeita de que o problema não é a estrutura familiar em que a criança vive, ou seja, o modelo de família, mas a falta de condições psicológicas adequadas nos adultos que têm como função o cuidado da criança.

A criança torna-se, então, "o problema" na avaliação dos pais, como se estivesse desprendida e solta dos laços e vínculos afetivos familiares, escolares e sociais; como se o que a acometesse fosse algo que diz respeito somente a ela, sem considerar o grupo em que está inserida, seja ele familiar, escolar ou social. 


\section{Considerações Finais}

Diante dos dados expostos e da discussão aqui desenvolvida, conclui-se que o profissional precisa estar atento tanto aos fatores intra quanto interpsíquicos no atendimento infantil. Essa posição do psicólogo leva a uma compreensão mais ampliada do que subjaz àquilo que se poderia chamar de patologia, ou seja, uma visão holística do sofrimento mental, das relações da criança com o seu ambiente.

As análises quantitativas sobre os atendimentos somadas às experiências de supervisão dos casos mostraram-se bastante ricas para a compreensão das questões mais amplas da população atendida, permitindo, além de algumas constatações epidemiológicas, discussões clínicas e levantamento de hipóteses que poderão se abrir em novas investigações, como, por exemplo: correlacionar as posições parentais e a sintomatologia infantil; identificar as condições mentais paternas e maternas durante os atendimentos familiares; estrutura versus funcionalidade das famílias que procuram atendimento para seus filhos; a expectativa dos pais em relação aos filhos e a percepção da necessidade de ajuda psicológica, dentre muitas outras.

Este trabalho reafirma - mais pela riqueza de questões levantadas do que por ter trazido conclusões - a importância da pesquisa, que encontra um lugar privilegiado nas clínicas-escola como um espaço de oferta dos serviços e ao mesmo tempo de condições para a realização de investigações sistematizadas.

\section{Referências}

Ancona-Lopez, M. (1984). Características da clientela de clínicas escola de psicologia em São Paulo. In R. M. Macedo (Org.), Psicologia e instituição: novas formas de atendimento (pp.24-46). São Paulo: Cortez.

Affonso, R. M. L., \& Mota, E. G. (2002). A relação pais-filhos: um estudo da dinâmica familiar. Psikhe, 7 (1), 8-56.

Barbosa, J. I. C., \& Silvares, E. F. M. (1994). Uma caracterização preliminar das clínicas-escola de Fortaleza. Estudos de Psicologia Campinas, 3 (11), 50-56.

Bauman, Z. (1998). O mal estar na pós-modernidade. Rio de Janeiro: Jorge Zahar.

Bleichmar, S. (1994). Do discurso parental à especificidade sintomática na psicanálise de crianças. In A.M.S. Rosenberg (Org.), Olugar dos pais na Psicanálise de crianças (pp.120-155). São Paulo: Escuta.
Borges, S. L. P. (1996). Caracterização da clientela da clínica São Marcos na área de atendimento infantil. Interações: Estudos e Pesquisas em Psicologia, 1 (1), 59-78.

Debieux, R. M. (2001). O não-dito familiar e a transmissão da história. Psyche, 5 (8),123-137.

Ferez-Carneiro, T. (1998). Clínica da família e do casal: tendências da demanda contemporânea. Interações: Estudos e Pesquisas em Psicologia, 6 (3), 23-32.

Graminha, S. S. V., \& Martins, M. A. O. M. (1993). Estudo das características da população que procura o serviço de atendimento infantil no Centro de Psicologia Aplicada da FFCLRP - USP. Psico, 1 (24),119-130.

Kristeva, J. (2002). As novas doenças da alma. Rio de Janeiro: Rocco.

Kupfer, M. C. (1994). Pais: melhor não tê-los? In A. M. S. Rosenberg (Org.), Olugar dos pais na psicanálise de criança (pp.99-119). São Paulo: Escuta.

Lipovetsky, G. (2004). O caos organizador. Folha de São Paulo, Caderno Mais! 14 de Março de 2004.

Organização Mundial da Saúde. (1993). Classificação de transtornos mentais e de comportamento da CID-10: descrições clínicas e diretrizes diagnósticas. Porto Alegre: Artes Médicas.

Ribeiro, M. J. (2004). O ensinar e o aprender em Winnicott: a teoria do amadurecimento emocional e suas contribuições à psicologia escolar. Tese de doutorado não-publicada, Pontifícia Universidade Católica de São Paulo.

Roudinesco, E. (2003). A família em desordem. Rio de Janeiro Zahar.

Rosenberg, A. M. S. (1994). A constituição do sujeito e o lugar dos pais na análise de crianças. In A. M. S. Rosenberg. O lugar dos pais na psicanálise de crianças (pp.21-59). São Paulo: Escrita.

Sanchez, N. A. (1985). Estudo epidemiológico de clientes da clínica-escola do departamento de psicologia da Universidade Federal de Uberlândia (MG). Dissertação de mestrado não-publicada, Departamento de Pós-Graduação em Psicologia, Pontifícia Universidade Católica de Campinas.

Santos, L. A. R. (2005). A criança, seu lugar na contemporaneidade e as implicações na clínica psicanalítica. Acesso em outubro 2, 2005, disponível em: http://www.estadosgerais.org/gruposvirtuais/santosa_crianca.shtml

Simionato-Tozo, S. M. P., \& Biasoli-Alves, Z. M. M. (1998). O cotidiano e as relações familiares em duas gerações. Paidéia: Cadernos de Psicologia e Educação, 14/15 (8), 137-150.

Souza, R. M. (1997). A criança na família em transformação: um pouco de reflexão e um convite à investigação. Psicologia Revista, 5, 33-51.

Recebido em: 8/1/2005

Versão final reapresentada em: 6/12/2005

Aprovado em: 3/5/2006 
